DOI: https://doi.org/10.31933/jimt.v2i5 Received: 20 April 2021, Revised: 27 Mei 2021, Publish: 4 Juli 2021

JIMT
JURNAL ILMU MANAJEMEN
TERAPII

\title{
DETERMINASI PRICE EARNING RATIO DAN RETURN SAHAM : CURRENT RATIO DAN NET PROFIT MARGIN
}

\author{
Nur Anisa ${ }^{1}$ \\ ${ }^{1)}$ Mahasiswa Program Magister Manajemen, Universitas Mercu Buana Jakarta, \\ anisaadjmain@gmail.com
}

Corresponding Author: Nur Anisa ${ }^{1}$

Abstrak: Perkembangan pasar modal saat ini sedang menjadi tren untuk melakukan investasi di berbagai kalangan dengan kemudahan akses berinvesatasi di pasar modal yang semakin mudah, dalam melakukan investasi diprlukan anlisis agar tidak terjadi kerugian dalam berinvestasi salah satunya adalah analisis fundamental dengan melihat rasio keuangan perusahaan tersbut. Rasio keuangan yang dapat digunakan salah satunya adalah Current Ratio (CR) dan Net Profit Margin (NPM) yang memiliki pangaruh terhadap Retrun saham, selain itu Rasio Pasar juga menjadi salah satu penilaian dalam menganalisis suatu perusahaan salah satunya adalah Price Earning Ratio (PER). Salah satu penlitian yang telah dilakukan oleh (Cynthia E. Kampongsina, 2020) dan (Kurniawan, Habibi, \& Arifin, 2020) menyebutkan bahwa Current Ratio dan Net Profit Margin memiliki pengaruh terhadap Price Earning Ratio (PER) dan Retrun Saham

Kata Kunci: Price Earning Ratio (PER), Retrun Saham, Current Ratio(CR), Net Profit $\operatorname{Margin}(\mathrm{NPM})$

\section{INTRODUCTION}

Perkembangan pasar modal di Indonesia setiap tahunnya mengalami peningkatan baik dari peningkatan jumlah investor maupun jumlah emiten yang go public. Berinvestasi pada instrument keuangan (financial asset) merupakan salah satu kegiatan yang digemari oleh para pemilik modal untuk mengembangkan dana yang dimiliki.

Dalam melakukan investasi salah satu faktor yang menentukan harapan akan pasar modal sebagai alternatif bagi investor adalah tingkat kemampuan investor memilih saham secara rasional yang dapat diukur dari cara mereka memilih saham yang memberikan Return maksimum pada tingkat risiko tertentu atau mempunyai risiko minimum pada tingkat Return tertentu. Return adalah penghasilan yang diterima atas investasi ditambah dengan perubahan harga pasar, sedangkan risiko sering dihubungkan dengan penyimpangan atau deviasi dari 
outcome yang diterima dengan yang diharapkan. Ekspektasi dari para investor terhadap investasinya adalah memperoleh Return atau tingkat pengembalian yang sebesar-besarnya dengan risiko tertentu. Return tersebut yang menjadi indikator untuk meningkatakan kekayaan para investor. Selain Return saham, Price Earning Ratio (PER), merupakan rasio yang menggambarkan apresiasi pasar terhadap kemampuan perusahaan dalam menghasilkan laba. Rasio ini mengindikasikan tingkatan kepercayaan investor pada kinerja masa depan perusahaan. Semakin tinggi Price Earning Ratio (PER), investor semakin percaya pada perusahaan. Pernyataan tersebut di dukung oleh penelitian yang telah dilakukan oleh (Muhammad \& Ali, 2018). Berdasarkan hal tersebut maka faktor-faktor fundamental yang dapat mempengaruhi Return saham dan Price Earning Ratio (PER) suatu perusahaan, dengan menggunakan Current Ratio (CR) dan Net Profit Margin (NPM).

Current Ratio (CR) adalah ukuran kinerja neraca keuangan terhadap likuiditas perusahaan. Rasio lancar ini mengukur apakah perusahaan memiliki sumber daya yang cukup untuk membayar hutangnya selama 12 bulan kedepan. Semakin tinggi Current Ratio (CR) maka semakin tinggi kepercayaan investor terhadap perusahaan. Net Profit Margin (NPM) merupakan rasio yang menunjukkan seberapa besar persentase laba bersih yang diperoleh dari setiap penjualan. Rasio ini menginterpretasikan tingkat efisiensi perusahaan, yakni sejauh mana kemampuan perusahaan menekan biaya-biaya operasionalnya pada periode tertentu. Semakin besar rasio ini semakin baik karena kemampuan perusahaan dalam mendapatkan laba melalui penjualan cukup tinggi serta kemampuan perusahaan dalam menekan biaya-biayanya cukup baik sehingga banyak investor menanamkan dananya. Hal tersebut mengakibatkan Return saham perusahaan ikut mengalami kenaikan.

Secara rinci tujuan dari penulisan "Literature Review Paper" ini adalah mengetahui pengaruh antara variabel exogen Current Ratio dan Net Profit Margin variabel endogen Price Earning Ratio dan Return Saham

1) Pengaruh Current Ratio terhadap Price Earning Ratio

2) Pengaruh Current Ratio terhadap Price Return Saham

3) Pengaruh Net Profit Margin terhadap Price Earning Ratio

4) Pengaruh Net Profit Magin terhadap Price Return Saham

5) Pengaruh Price Earning Ratio terhadap Return Saham

\section{KAJIAN TEORI}

\section{Current Ratio (CR)}

(Dr. Pardomuan Sihombing, 2018) menyatakan Current Ratio mengukur kemampuan perusahaan memenuhi utang jangka pendeknya (jatuh tempo kurang dari satu tahun) dengan menggunakan aktiva lancar, dapat dirumuskan sebagai berikut :

$$
\text { Current Ratio }=\frac{\text { Aktiva Lancar }}{\text { Utang lancar }}
$$

Semakin besar Current Ratio maka semakin besar kemampuan perusahaan untuk membayar kewajiban lancarnya. Namun Current Ratio yang tinggi juga berpengaruh kurang baik terhadap tingkat profitabilitas perusahaan, dengan kata lain aktiva lancar menghasilkan tingkat Return yang rendah dibandingkan aktiva tetap. 
Current Ratio sudah banyak di teliti oleh peneliti sebelumnya di antaranya oleh, (Indriawati, 2020), (Wahyuni \& Hafiz, 2018), (Cynthia E. Kampongsina, 2020), (Winarsa, 2021).

\section{Net Profit Margin (NPM)}

(Dr. Pardomuan Sihombing, 2018) mengatakan bahwa rasio Net Profit Margin (NPM) nerupakan indikasi kemampuan manajemen perusahaan mengoperasikan bisnisnya dengan tingkat keberhasilan yang baik. Net Profit Margin adalah rasio untuk mengukur hubungan antara laba bersih dengan penjualan perusahaan yang dapat dirumuskan sebagai berikut:

$$
\text { Net Profit Margin }(N P M)=\frac{\text { Laba Bersih Setelah Pajak dan Bunga }}{\text { Penjualan }}
$$

Berdasarkan penjelasan diatas maka dapat disimpulkan bahwa Net Profit Margin (NPM) adalah rasio yang digunakan untuk menunjukkan kemampuan perusahaan dalam menghasilkan keuntungan bersih setelah dipotong pajak. Rasio ini digunakan untuk mengukur laba bersih yang dihasilkan oleh setiap penjulaan. Rasio ini juga menunjukan kemampuan manejemen dalam mengemudikan perusahaan secara cukup berhasil untuk menyisakan margin tertentu sebagai kompensasi yang wajar bagi pemilik yang telah menyediakan modalnya untuk suatu sekuritas.

Penelitian tentang Net Profit Margin telah banyak dikaji oleh penelitian sebelumnya seperti penelitian yang dikembangkan oleh, (Lestari, Dewi, \& Chomsatu, 2019), (Arramdhani \& Cahyono, 2020), (Wahyuni, Susanto, \& Asakdiyah, 2020), (Sari, Hermuningsih, \& Cahya, 2021).

\section{Price Earning Ratio (PER)}

(Ross, Wesrefield, Jordan, lim, \& Tan, 2015) menyatakan bahwa Price Earning Ratio (PER) adalah rasio harga terhadap laba, dimana harga saham per lembar dibagi laba per saham. Nilai Price Earning Ratio (PER) yang tinggi menunjukkan ekpektasi investor tentang prestasi perusahaan di masa mendatang cukup tinggi. Sehingga bagi para investor, semakin tinggi Price Earning Ratio (PER) maka pertumbuhan laba yang diharapkan juga akan mengalami kenaikan. Price Earning Ratio (PER) dapat diformulasikan sebagai berikut:

$$
\text { Price Earning Ratio }(P E R)=\frac{\text { Harga Saham }}{\text { Laba Per Lembar Saham }}
$$

Berdasarkan penjelasan diatas dapat disimpulkan bahwa Price Earning Ratio (PER) adalah rasio antara harga saham dengan pendapatan setiap lembar saham, dan merupakan indikator perkembangan atau pertumbuhan perusahaan di masa yang akan datang (prospects of the firm). Price Earning Ratio (PER) merupakan perbandingan antara harga pasar suatu saham (market price) dengan Earning Per Share (EPS) dari saham yang bersangkutan. Kegunaan dari Price Earning Ratio (PER) adalah untuk melihat bagaimana pasar menghargai kinerja saham suatu perusahaan terhadap kinerja perusahaan yang dicerminkan oleh EPS-nya.

Penelitian tentang Price Earning Ratio telah banyak dikaji oleh penelitian sebelumnya seperti penelitian yang dikembangkan oleh (Indriawati, 2020), (Sari, Hermuningsih, \& Cahya, 2021), (Wahyuni, Susanto, \& Asakdiyah, 2020), (Zayyinah \& Firmansyah, 2021)

\section{Return Saham}


Return merupakan hasil yang diperoleh dari investor yang dapat berupa realisasi yang sudah terjadi dan Return ekspektasi yang diharapkan akan terjadi dimasa mendatang. Investor harus melakukan penilaian harga saham terlebih dahulu agar dapat memperoleh tingkat pengembalian saham (Return) dan keuntungan yang sesuai dengan yang diharapkan. Menurut (Dr. Pardomuan Sihombing, 2018) Return pada umumnya dimaksudkan sebagai tingkat keuntungan atau tingkat pengembalian dari sebuah aset atau investasi periode tertentu. Dengan kata lain, Return adalah pendapatan actual tahunan yang diterima, ditambah dengan setiap perubahan harga dipasar.

Saham dikenal dengan karakteristik high risk-high Return. Artinya saham merupakan surat berharga yang memberikan peluang keuntungan tinggi namun juga berpotensi risiko tinggi. Saham memungkinkan pemodal untuk mendapatkan Return berupa capital gain jika harga saham sekarang (Pt) lebih tinggi dari harga saham periode sebelumnya (Pt-1). Namun, seiring dengan berfluktuasinya harga saham, ada kalanya pemodal harus menjual saham dengan harga jual lebih rendah daripada harga beli, maka hal tersebut disebut dengan capital loss. Secara matematis, formulasi Return saham dapat dirumuskan sebagai berikut:

$$
\boldsymbol{R}_{t}=\frac{\boldsymbol{P}_{t}-\boldsymbol{P}_{t-1}}{\boldsymbol{P}_{t-1}} \times 100 \%
$$

Penelitian tentang Return Saham telah banyak dikaji oleh penelitian sebelumnya seperti penelitian yang dikembangkan oleh (Arramdhani \& Cahyono, 2020) (Cynthia E. Kampongsina, 2020) (Lestari, Dewi, \& Chomsatu, 2019) (Winarsa, 2021), (Prasetia, Ahmar, Mulyadi, \& Suyanto, 2020).

\section{METODE PENULISAN}

Jenis penelitian yang digunakan dalam penelitian ini adalah metode penelitian kuantitatif dengan pendekatan deskriptif. Metode penelitian kuantitatif adalah metode penelitian yang didasarkan pada filsafat positivism, digunakan dalam meneliti sample dan populasi penelitian, teknik pengambilan sampel pada umumnya dilakukan secara random, pengumpulan data menggunakan instrumen penelitian, analisis data bersifat kuantitatif/statistik dengan tujuan untuk menguji hipotesis yang ditentukan (Sugiyono, 2013). Adapun penelitian deskriptif merupakan metode yang bertujuan untuk menjelaskan atau mendeskripsikan suatu peristiwa, keadaan, objek atau orang, atau segala sesuatu yang terkait dengan variable-variabel yang bisa dijelaskan baik menggunakan angka-angka maupun kata-kata (Hidayat, 2010). Penelitian deskriptif dalam penelitian ini dimaksudkan untuk mendapatkan gambaran dan keteranganketerangan terkait pengaruh Current Ratio dan Net Profit Margin terhadap Price Earning Ratio dan Return saham.

Selanjutnya dibahas secara mendalam pada bagian yang berjudul" Determinasi Price Earning Ratio Dan Return Saham : Current Ratio Dan Net Profit Margin" (Related Literature) atau Kajian pustaka( "Review of Literature"), sebagai dasar perumusan hipotesis dan selanjutnya akan menjadi dasar untuk melakukan perbandingan dengan hasil atau temuantemuan yang terungkap dalam penelitian, (Ali \& Limakrisna, 2013).

\section{PEMBAHASAN}

Berdasarkan penelitian yang sudah banyak dilakukan mengenai determinasi Price Earning Ratio (PER) dan Retrun Saham terhadap rasio keuangan agar para investor dapat dengan secara maksimal menempatkan modalnya untuk berinvestasi yang bertujuan mendaptkan keuntungan yang maskimal. Rasio keuangan yang digunakan untuk mengukur pengaruh Price Earning 
Ratio (PER) dan Retrun Saham adalah Current Ratio (CR) dan Net Profit Magrin (NPM), kedua rasio keuangan ini memiliki pengaruh terhadap Price Earning Ratio (PER) dan Retrun Saham, berikut penelitian yang sudah dilakukan mengenaih masing-masing pengaruh variabel yang akan di teliti, diantaranya :

\section{Pengaruh Current Ratio terhadap Price Earning Ratio}

(Kurniawan, Habibi, \& Arifin, 2020) menemukan bahwa Current Ratio secara parsial berpengaruh terhadap Price Earning Ratio, hal tersebut dibuktikan dengan nilai signifikan lebih kecil dari tingkat signifikansi yang digunakan yaitu 0,05 .

\section{Pengaruh Current Ratio terhadap Price Return Saham}

Menurut penelitian yang dilakukan oleh Menurut penelitian yang dilakukan oleh Putu Sari indiyani, Ni Made Sunrsih, dan Ida Ayu Nyoman Yuliastuti (2020) menunjukan Current Ratio (CR) berpengaruh positif dan signifikan terhadap Return saham.

\section{Pengaruh Net Profit Margin terhadap Price Earning Ratio}

Hasil penelitian (Zamzami \& Dr. Aulia Fuad Rahman) menunjukan bahwa Net Profit Margin berpengaruh positif terhadap Price Earning Ratio.

\section{Pengaruh Net Profit Magin terhadap Price Return Saham}

Menurut penelitian yang dilakukan oleh Öztürk, Karabulut (2018) menunjukan bahwa hasil variabel Net Profit Margin (NPM) berpengaruh positif dan signifikan terhadap Return saham.

\section{Pengaruh Price Earning Ratio terhadap Return Saham}

Menurut hasil penelitian yang dilakukan oleh (Risdiyanto \& Suhermin) menyebutkan bahwa Price Earning Ratio berpengaruh signifikan terhadap retrun saham.

\section{Conceptual Framework}

Berdasarkan rumusan masalah penulisan artikel ini dan kajian studi literature review baik dari buku dan artikel yang relevan, maka di perolah rerangka artikel ini seperti di bawah ini.

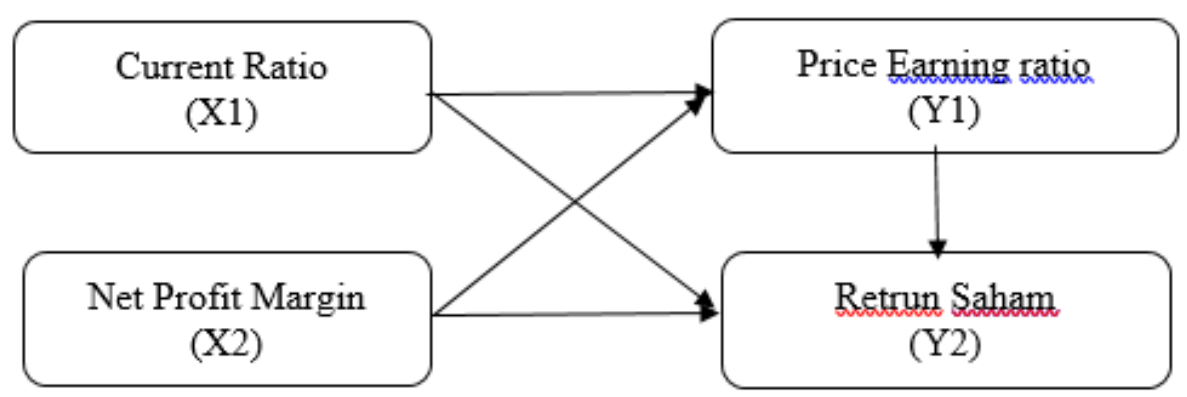

Gambar 1: Conceptual Framework

Current Ratio dan Net Profit Margin memiliki hubungan dan berpengaruh terhadap Price Earning Ratio dan Retrun Saham. Selain dari variabel Current Ratio dan Net Profit 
Margin yang mempengaruhi Price Earning Ratio dan Retrun Saham pembelian masih banyak variabel lain yang mempengaruhinya, di antaranya adalah variabel:

1) Retrun On Aset (x3): (Ali, Evi, et al., 2018), (Prihartono \& Ali, 2020), (Richardo et al., 2020), (Mappesona et al., 2020), (Sulistiorini \& Ali, 2017), (Hairiyah \& Ali, 2017), (Ali, Narulita, et al., 2018), and (Brata et al., 2017).

2) Debt Equit Ratio (x4) : (M \& Ali, 2017),(Limakrisna \& Ali, 2016), (Yunita \& Ali, 2017), (Yunita \& Ali, 2017), (Ali \& Mappesona, 2016), (Ali, Evi, et al., 2018), (Sitio \& Ali, 2019), and (Anggita \& Ali, 2017).

3) Retrun On Equity (x5): (M \& Ali, 2017), (Ali, Narulita, et al., 2018), (M \& Ali, 2017), (Ali, Evi, et al., 2018), (Prihartono \& Ali, 2020), (Riyanto et al., 2017), (Maisah \& Ali, 2020), (Brata et al., 2017), (Thanh Nguyen et al., 2019), (Ali, 2019), and (Anggita \& Ali, 2017).

\section{KESIMPULAN DAN SARAN}

\section{Kesimpulan}

Hypothesis testing research adalah penelitian yang bertujuan untuk mengembangkan hipotesis dan mengujinya secara empiris atas suatu permasalahan tertentu (Ali \& Limakrisna, 2013). Berdasarkan rumusan artikel, hasil dan pembahasan, maka dapat di di rumuskan hipotesis untuk riset selanjutnya:

1. Current Ratio berpengaruh terhadap Price Earning Ratio.

2. Current Ratio berpengaruh terhadap Retrun Saham.

3. Net Profit Margin berpengaruh terhadap Price Earning Ratio.

4. Net Profit Margin berpengaruh terhadap Keputusan Pembelian.

5. Price Earning Ratio berpengaruh terhadap Retrun Saham.

\section{Saran}

Bersdasarkan Kesimpulan di atas, maka saran pada artikel ini adalah bahwa masih banyak factor lain yang mempengaruhi Price Earning Ratio dan Retrun Saham, selain dari Current Ratio dan Net Profit Margin, oleh karena itu masih di perlukan kajian yang lebih lanjut untuk mencari faktor-faktor lain apa saja yang dapat memepengaruhi Price Earning Ratio dan Retrun Saham selain yang di teliti pada arikel ini.

\section{DAFTAR PUSTAKA}

Arramdhani, s., \& cahyono, k. E. (2020). Pengaruh npm, roa, der, dpr terhadap Return saham. Jurnal ilmu dan riset manajemen, vol 9 no.4.

Cynthia e. Kampongsina, s. M. (2020). Pengaruh Current Ratio, debt to equity dan Return on equity terhadap Return saham pada perusahaan farmasi yang terdaftar di bei (periode 2015-2019). Jurnal emba, vol.8 no.4.

Dr. Pardomuan sihombing, m. (2018). Corporate financial management. Bogor, indonesia: ipb press.

Indriawati, m. N. (2020). Pengaruh Current Ratiodan earning pershareterhadap harga saham dengan Price Earning Ratio sebagai variabel moderasi. Borneo student research, vol 1 , no 2 . 
Kurniawan, a., habibi, a., \& arifin, m. B. (2020). Pengaruh Current Ratio, debt to equity ratio,inventory turnover ratio, Return on equityterhadap Price Earning Ratio. Almashrof: jurnal keuangan dan perbankan syariah, vol. 1 no. 1.

Lestari, s., dewi, r. R., \& chomsatu, y. (2019). Pengaruh eps, npm, per dan inflasi terhadap Returnsahampada perusahaan bumn go public. Jurnal unpam, vol 2, no.1.

Muhammad, s., \& ali, g. (2018). Relationship between fundamental analysis and stock Return based on the panel data analysis; evidence from karachi stock exchange. Research journal of finance and accounting, vol 9 no 3. Saudi arabia.

Prasetia, a., ahmar, n., mulyadi, j., \& suyanto, s. (2020). Faktor yang mempengaruhi Return saham perusahaan properti dalam indeks saham syariah indonesia. Jurnal manajemen kewirausahaan, vol. 17 no.2.

Risdiyanto, \& suhermin. (t.thn.). Pengaruh roi, eps dan per terhadap Return saham pada perusahaan farmasi . Jurnal ilmu dan riset manajemen, volume 5, nomor 7.

Ross, s. A., wesrefield, r. W., jordan, b. D., lim, j., \& tan, r. (2015). Pengantar kaeuangan perusahaan (fundamentals of corporate finance). Edisi global asia. Jakarta: salemba empat.

Sari, r. P., hermuningsih, s., \& cahya, a. D. (2021). Pengaruh Current Ratio, debt equity ratio, total asset turnover terhadap Price Earning Ratio. Jurnal proaksi, vol 8, no. 1.

Wahyuni, i., susanto, a., \& asakdiyah, s. (2020). Pengaruh debt to equity ratio (der), currentratio (cr), Return on equity (roe), dan Net Profit Margin (npm) terhadap Price Earning Ratio (per) perusahaan sub sektor perkebunan yang terdaftar pada bursa efek indonesia periode tahun 2014-2017. Management, business, and accounting (mbia), vol 19, no. 1.

$\begin{array}{lllllll}\text { Wahyuni, } & \text { s. } & \text { F., } & \& & \text { hafiz, } & \text { m. } & \text { S. }\end{array}$ Pengaruhcr,derdanroaterhadapdprpadaperusahaanmanufakturdibei. Jurnal ekonomi \& ekonomi syariah, vol 1 no 2.

Winarsa, r. O. (2021). Pengaruh Current Ratio(cr), Return on assets (roa) dan debt to equity ratio (der) terhadap Return sahamperusahaan sub sektor industri kimiayang terdaftar di bursa efek indonesiaperiode 2014-2018. Jurnal semarak : jurnal ilmiah prodi manajemen universitas pamulang, vol.4,no.1, hal (70-79).

Zamzami, r. E., \& dr. Aulia fuad rahman, s. M. (t.thn.). Pengaruh kinerja keuangan terhadapPrice Earning Ratio.

Zayyinah, z., \& firmansyah, f. (2021). Pengaruh Return on equity (roe), debt to equity ratio (der), dan Price Earning Ratio (per) terhadap Return saham pada perusahaan infrastruktur, utilitas dan transportasi di daftar efek syariah periode 2017-2018. Shafin: sharia finance and accounting journal, vol 1 no. 1. 